\title{
Laccase Production by Trameteshirsuta, Characterization, and Its Capability of Decoloring Chlorophyll
}

\author{
JIAYANG LIU ${ }^{1,2}$, WENHUA LIU ${ }^{2}$, YUJIE CAI ${ }^{2}$, XIANGRU LIAO ${ }^{2 *}$, \\ QINGGUO HUANG ${ }^{3}$ and XIAOHUI LIANG ${ }^{4}$
}

\author{
${ }^{1}$ Fermentation Technology Division, School of Bioengineering, Huanghuai University, Zhumadian 463000, China \\ ${ }^{2}$ The Key Laboratory of Industrial Biotechnology, Ministry of Education, School of Biotechnology, \\ Jiangnan University, Wuxi 214122, China \\ ${ }^{3}$ Department of Crop and Soil Sciences, University of Georgia, Griffin, Georgia 30223, United States \\ ${ }^{4}$ Energy Research Institute of Shandong Academy of Sciences, Jinan 250014, China
}

Submitted 7 May 2014, Revised 21 July 2014, Accepted 29 July 2014

\begin{abstract}
The present study focused on laccase production, characterization, and its involvement in chlorophyll decolorization. Extracellular laccase, with the highest activity of $11 \mathrm{U} / \mathrm{ml}$ on day 8, was efficiently produced from Trametes hirsuta in 51 bioreactor with optimized media comprising dual carbon sources, glucose and water hyacinth. A laccase was then purified from the supernatant to homogeneity with purification fold of 9.51 and recovery of $39.8 \%$ and an estimated molecular mass of $62 \mathrm{kDa}$ by SDS-PAGE. The laccase showed activity at $\mathrm{pH} 2-6$ and temperature $30-80^{\circ} \mathrm{C}$ and was relatively thermally stable at below $70^{\circ} \mathrm{C}$ and neutral $\mathrm{pH}$. The laccase was applied to decolorize chlorophyll under different factors: temperature, $\mathrm{pH}$, mediator, metal ions, and enzyme dosage. Other fungal laccases were also found to be able to degrade chlorophyll with rating from $52 \%$ to $88 \%$ following $1 \mathrm{~h}$ treatment with two laccase dosages $(5 \mathrm{or} 10 \mathrm{U} / \mathrm{ml})$ in the absence of any other mediators at room temperature. These findings may be an important step in developing new, important, and commercially viable industrial applications for laccase enzymes.
\end{abstract}

Ke y w ords: laccase; decolorization; chlorophyll; purification; white-rot fungi

\section{Introduction}

Laccases (EC 1.10.3.2) are copper-containing green catalysts that belong to the oxidoreductase class of enzymes. Laccases occur widely in nature and can be found in plants, animals, insects, bacteria, and most fungi (Mayer and Staples, 2002). Up to date, the intensively studied fungi belong to the genera Pycnoporus, Pleurotus, Trametes, and Phanerochaete (Couto and Sanromán, 2007; Eggert et al., 1996; Faraco et al., 2008; Tien and Kirk, 1988). The broad occurrence of laccase in nature has actually prompted scientists worldwide to screen for and produce laccase from various microorganisms for potential industrial and environmental purposes. Laccases are able to oxidize a wide range of phenolic and non-phenolic substrates via the reduction of molecular oxygen to water in the absence or presence of organic mediators (Hsu et al., 2012). Laccases have been applied to industrial processes such as hormone transformation, chemical synthesis, dyes and wastewater decolorization, food product formulations, textile processing, and bioremediation (Baldrian, 2006; Lu et al., 2009; Pividori et al., 2009; Sadhasivam et al., 2010; Santhiago and Vieira, 2007). These various industrial applications attest to the wide spectrum of catalytic activities of laccases on different substrates. However, the catalytic capabilities of laccase have yet to be fully explored.

Chlorophyll, a green pigment existing in five distinct forms $(a, b, c, d, f)$, plays an essential role in oxygenic photosynthesis for plants. Chlorophyll allows the chloroplast to capture and employ sunlight to convert $\mathrm{H}_{2} \mathrm{O}$ and $\mathrm{CO}_{2}$ into chemical energy with a concomitant release of oxygen (Chen et al., 2010). Chlorophyll $a$ is the most abundant and commonly found pigment in photosynthetic organisms and has been shown to be indispensible for photosynthesis and that other forms of chlorophyll serve as accessory pigments according to the structures and functions (Chen et al., 2010). Chlorophyll mainly absorbs blue and red light with green

\footnotetext{
* Corresponding author: XR. Liao, The Key Laboratory of Industrial Biotechnology, Ministry of Education, School of Biotechnology, Jiangnan University, Wuxi 214122, China; phone: +86 13771104596; e-mail: liaoxiangru@163.com
} 
and near-green light mostly reflected, thus giving leaves and other chlorophyll-containing tissues of living plants a green appearance. Postharvest crops and plants readily lose their green appearance during senescence. The loss of green color is attributed to gradual degradation of chlorophyll mediated by peroxidases (Hynninen et al., 2010; Yamauchi et al., 2004). An existing study had shown that chlorophyll can be bleached by peroxidase extracted from strawberry (Martínez et al., 2001). While both laccases and peroxidases belong to the oxidoreductase family, laccases' ability to directly decolorize or degrade chlorophyll was previously unknown.

We have recently isolated a wild fungus from Chinese chestnut as a potential laccase producer using an optimized medium with glucose as sole carbon source. To further boost laccase productivity, an additional carbon source, a lignocellulosic waste water hyacinth, was also added to optimized media to stimulate laccase excretion by the fungus. During fungal cultivation for laccase production, a dramatic decrease in the green color of the medium was simultaneously observed, suggesting that degreening of chlorophyll may be associated with laccase activity to some extent via a possible laccase-catalyzed chlorophyll decolorization. This study focused on laccase production using dual carbon sources and on the purification and characterization of laccase. This is the first report on the capability of laccase to decolorize chlorophyll in vitro and the effect of certain factors affecting the reaction reaction was ascertained.

\section{Experimental}

\section{Materials and Methods}

Fungal strain for laccase production. Fungus L19, newly isolated from a Chinese chestnut (located in a city park in Wuxi, China), was characterized as Trametes hirsuta SYBC-L19 based on ITS internal sequencing analysis combined with morphologic characteristics (the ITS sequence was deposited in GenBank under accession number JX861099). This fungus was employed in this study for laccase production, purification and subsequent chlorophyll decolorization. The fungus was grown on potato dextrose agar (PDA) plate added with $0.04 \%$ guaiacol at $30^{\circ} \mathrm{C}$ to indicate the excretion of extracellular laccase by reddish halocircle. The fungus was subcultured on PDA plate prior to liquid-state fermentation; otherwise it was stored on PDA slants at $4^{\circ} \mathrm{C}$ in the key laboratory at Jiangnan University, Wuxi, China.

Laccase production via liquid-state fermentation. Seed culture was obtained by growing the fungus in a medium containing $5 \%$ glucose, $1 \%$ yeast extract, and
$0.5 \%$ peptone. Laccase was produced by cultivating the fungus L19 via liquid-state deep fermentation in a two carbon sources containing optimized medium composed of: water hyacinth (stem) $41.0 \mathrm{~g} / \mathrm{l}$ (air-dry weight), glucose $30.0 \mathrm{~g} / \mathrm{l}$, corn steep powder $50.8 \mathrm{~g} / \mathrm{l}$, ammonium tartrate $2.9 \mathrm{~g} / \mathrm{l}$, tween $800.5 \mathrm{~g} / \mathrm{l}, \mathrm{CuSO}_{4} \cdot 5 \mathrm{H}_{2} \mathrm{O}$ $0.6 \mathrm{~g} / \mathrm{l}$, vanillin $0.54 \mathrm{mmol} / \mathrm{l}, \mathrm{NaH}_{2} \mathrm{PO}_{4} \cdot 2 \mathrm{H}_{2} \mathrm{O} 2.0 \mathrm{~g} / \mathrm{l}$, $\mathrm{MgSO}_{4} \cdot 7 \mathrm{H}_{2} \mathrm{O} 0.5 \mathrm{~g} / \mathrm{l}, \mathrm{MnSO}_{4} \cdot \mathrm{H}_{2} \mathrm{O} 0.1 \mathrm{~g} / \mathrm{l}$. The liquid culture medium with $\mathrm{pH} 4.0$ was subjected to autoclave at $121^{\circ} \mathrm{C}$ for $20 \mathrm{~min}$, followed by inoculation of seed culture (inoculum of $8 \%$ ) after the sterilized medium cooled down. Cultivation was carried out in $250 \mathrm{ml}$ Erlenmeyer flasks with $40 \mathrm{ml}$ solution on a rotary shaker at $200 \mathrm{rpm}$ at temperature of $30^{\circ} \mathrm{C}$. The laccase activity was accordingly determined everyday by taking $0.2 \mathrm{ml}$ of samples from flasks. As for laccase production in bioreactor, seed culture (inoculum of 10\%) was transferred into a 5-L stirred bioreactor (Shanghai Baoxing Bioengineering L.t.d., China) containing 4- $\mathrm{L}$ above mentioned medium under condition of a constant temperature of $30^{\circ} \mathrm{C}$ and an aeration rate of $2 \mathrm{l} / \mathrm{min}$. A $20 \mathrm{~mL}$ culture broth was sampled every day for determination of laccase activity and reducing sugar content while $\mathrm{pH}$ of the culture was recorded by a $\mathrm{pH}$ glass electrode installed in the reactor. Reducing sugar content was determined using dinitrosalicylic acid method with glucose as a standard. After cultivation was finished, the culture broth was filtered and centrifuged at $4,000 \mathrm{~g}$ for $20 \mathrm{~min}$ to obtain the supernatant (crude laccase) for the following purification.

Determination of laccase activity. Laccase activity was spectrophotometrically determined with 2,6-dimethoxyphenol (DMP, Fluka, Switzerland) as a substrate by monitoring the oxidized product at $469 \mathrm{~nm}\left(\varepsilon=49.5 \mathrm{mM}^{-1} \mathrm{~cm}^{-1}\right)$ (Litthauer et al., 2007). The assay system $(3 \mathrm{ml})$ contained $0.1 \mathrm{ml}$ of the liquid sample, $0.5 \mathrm{ml}$ of $10 \mathrm{mM}$ DMP and $2.4 \mathrm{ml}$ sodium citrate-phosphate buffer (0.1 M, pH 3.5). One unit of enzyme activity was defined as the amount of enzyme that oxidized $1 \mu \mathrm{mol}$ of DMP per min at $45^{\circ} \mathrm{C}$. Protein content was estimated according to Bradford using bovine serum albumin (BSA) as a standard.

Purification of laccase and sodium dodecyl sulfatepolyacrylamide gel electrophoresis (SDS-PAGE). Laccase was purified with three steps in-sequence: ammonium sulfate precipitation, HiTrap DEAE FF anion exchange chromatography, and Superdex 75 10/300 gel filtration chromatography. Specifically, the laccase enzyme was obtained by collecting the precipitate generated from the crude laccase with saturation of $60-80 \%$ with ammonium sulphate, after which the precipitate with laccase was re-dissolved in sodium citrate phosphate buffer (pH 6.0, $20 \mathrm{mM}$ ). The re-dissolved laccase enzyme was then filtered through a millipore filter of $0.45 \mu \mathrm{m}$ cellulose membrane by a vacuum pump. 
The filtrate was then loaded onto a pre-equilibrated HiTrap DEAE FF anion exchange column with $0.02 \mathrm{M}$ sodium phosphate buffer ( $\mathrm{pH} 6.0$ ) and eluted with a linear gradient $(0-1 \mathrm{M} \mathrm{NaCl}$ in $500 \mathrm{ml}$ buffer) at $1 \mathrm{ml} / \mathrm{min}$. The fractions with laccase activity were pooled and then loaded onto a Superdex $7510 / 300$ gel filtration column equilibrated with $0.02 \mathrm{M}$ sodium phosphate buffer, $\mathrm{pH} 6$ to obtain purified laccase that was kept at $4^{\circ} \mathrm{C}$ for further enzyme characterization. The purity of laccase was further verified by SDS-PAGE, containing a $12 \%$ polyacrylamide gel with $0.1 \%$ SDS which was stained with Coomassie brilliant blue G-250 to visualize the protein band. The molecular mass of the purified laccase was then calculated from its immigrating distance on SDS-PAGE referring to the standard markers (TaKaRa, Dalian branch in China, Japan).

Partial properties of purified laccase. The effect of temperature on laccase activity was assessed by incubating the assay mixtures at different temperatures, ranging from $30^{\circ} \mathrm{C}$ to $80^{\circ} \mathrm{C}$ with an interval of $10^{\circ} \mathrm{C}$. The assay mixture was kept at the selected temperatures for $5 \mathrm{~min}$ prior to the addition of laccase for activity measurement. The thermal stability of laccase was evaluated by incubating the samples at above temperatures for $1 \mathrm{~h}$ before adding it to the assay mixture (at the optimal temperature $60^{\circ} \mathrm{C}$ and $\mathrm{pH} 3.0$ ) to measure residual laccase activity.

The effect of $\mathrm{pH}$ on laccase activity was assessed by preparing the assay mixture in sodium phosphate buffer with $\mathrm{pH}$ ranging from 2.0 to 8.0 with an interval of 1 and examined at optimal temperature $60^{\circ} \mathrm{C}$. The corresponding stability towards $\mathrm{pH}$ was evaluated by incubating the laccase samples at above $\mathrm{pHs}$ for $1 \mathrm{~h}$ before adding it to the assay mixture (at the optimal temperature $60^{\circ} \mathrm{C}$ and $\mathrm{pH} 3.0$ ) to measure residual laccase activity.

Preparation of chlorophyll. Fresh spinach (Spinacia oleracea), with height of around $20 \mathrm{~cm}$ and leaves about $10 \mathrm{~cm}$ long and $5 \mathrm{~cm}$ broad, was purchased from a local supermarket. Chlorophyll was extracted from the spinach using a modification of the method used by Martinez et al. (2001). Specifically, ten grams of fresh spinach leaves were mixed with $5 \mathrm{ml}$ of $95 \%$ ethanol and a small amount of silica sand and calcium carbonate. This mixture wan then put in a mortar and ground to slurry. The slurry was then extracted with $10 \mathrm{ml}$ of $95 \%$ ethanol at $60^{\circ} \mathrm{C}$ and then filtered to remove insoluble solids. The typical absorption peak of extracted chlorophyll was obtained by scanning the chlorophyll sample using a UV-Vis spectrophotometer (DU ${ }^{\oplus} 640 \mathrm{~B}$, Beckman, USA). Absorbance at $663 \mathrm{~nm}$ was used for the subsequent decolorization analysis.

Decolorization of chlorophyll mediated by laccase. Disappearance of green color was determined spectrophotometrically by monitoring the absorbance at $663 \mathrm{~nm}$, the wavelength of maximum absorbance for chlorophyll. The rate of decolorization was calculated by the following formula: percent chlorophyll removal $(\%)=\left(1-A_{f} / A_{i}\right) \times 100$, in which $A_{i}$ represents the initial absorbance at the wavelength $663 \mathrm{~nm}$ without laccase, while $A_{f}$ means the final absorbance of chlorophyll after enzymatic reaction referred to the description by Cristóvão et al. (2009). The decolorization system ( $2.5 \mathrm{ml}$ total) comprised the following: $2.0 \mathrm{ml}$ buffer (citric-phosphate, $20 \mathrm{mM}, \mathrm{pH} 4.0$ ), $0.1 \mathrm{ml}$ laccase enzyme $(10 \mathrm{U} / \mathrm{ml}), 0.2 \mathrm{ml}$ chlorophyll solution, $0.1 \mathrm{ml}$ deionized water, and $0.1 \mathrm{ml}$ Triton X-100 (a surfactant). The reaction conditions were $50^{\circ} \mathrm{C}$ and without light. Upon completion of the enzymatic reaction for a certain period and prior to UV-vis absorbance measurement at $663 \mathrm{~nm}, 2.5 \mathrm{ml}$ of ethanol followed by $5.0 \mathrm{ml}$ of hexane was added to the solution over a 2 -h period. The experiment was performed in triplicate.

Factors affecting laccase-mediated chlorophyll decolorization. Some parameters were investigated with respect to their effects on laccase-mediated chlorophyll decolorization.

Temperature. Initial reaction temperature $\left(50^{\circ} \mathrm{C}\right)$ was adjusted to $30,40,50,60,70^{\circ} \mathrm{C}$, respectively, to study the influence of various temperatures on decolorization rate of chlorophyll. The enzymatic reactions ( $1 \mathrm{U}$ per system) were terminated at 10, 30, 60, and 100 min for determination of chlorophyll decolorization rate, from which an optimum temperature was identified.

pH. Laccase-mediated chlorophyll decolorization system was performed in varied $\mathrm{pH}$ buffers (citric-phosphate, $0.1 \mathrm{M}$ ) ranging from 3 to 8 with an interval of 1 . Laccase was applied at $1 \mathrm{U}$ per system. The enzymatic reactions were terminated at $10,30,60$, and $100 \mathrm{~min}$ for determination of chlorophyll decolorization rate, from which an optimum $\mathrm{pH}$ value was identified.

Ionic conditions The $2.4 \mathrm{ml}$ buffer was modified with $2.3 \mathrm{ml}$ buffer plus $0.1 \mathrm{ml}$ various metal ion solution with the final concentration of 1 and $10 \mathrm{mM}$, respectively. Other conditions remained the same as above. Control samples were performed with water in place of the metal ion solution. Decolorization was assayed after 1-h enzymatic reaction.

Mediators Seven phenolic compounds and ATBS as well as ascorbic acid were selected to study their potential influences on laccase-mediated chlorophyll decolorization. All mediators were examined under three increasing levels with the final concentration of $0.5,2.0$, and $5.0 \mathrm{mM}$, respectively. Control treatments were performed in the same procedure without addition of mediators.

Laccase dosage Increasing laccase levels, from 1 to $30 \mathrm{U} / \mathrm{ml}$, were applied to study the influence on decolorization rate of chlorophyll. The enzymatic reactions were terminated at different duration for determination 
of decolorization rate of chlorophyll, from which an optimum laccase dosage was identified.

Laccase source. Different laccases in form of crude extract from various fungi were employed in place of the purified fungus L19 laccase to examine their capability to mediate chlorophyll decolorization. These fungi were all stock cultures in the key laboratory at Jiangnan University (Wuxi, China), including: Trametes trogii SYBC-1, Pycnoporus sp. SYBC-L3 (Liu et al., 2013), T. hirsuta SYBC-L5, Pycnoporus cinnabarinus SYBC-L7, Shiraia sp. SUPER-H168 (Yang et al., 2013), from each of which laccase was produced under their respectively optimized culture media. The supernatant derived from culture broth by filtrating biomass was termed crude enzyme extract, which were applied to treat chlorophyll under above decolorization system for $1 \mathrm{~h}$.

Data collecting and figure plotting. Determinations, including enzyme assay and decolorization of chlorophyll, were all performed in triplicate. For laccase characterization, laccase was expressed in relative activity, taking the highest mean value as $100 \%$. The software Origin 8 was employed to calculate mean value/SD and plot the data. Chemical structures of chlorophyll and mediators were generated using software ACD/ ChemSketch.

\section{Results}

Production and purification of laccase. T. hirsuta SYBC-L19 produced approximately $4 \mathrm{U} / \mathrm{ml}$ of laccase in a single carbon source (glucose) medium while doubled its laccase production when another carbon source (water hyacinth) was supplemented into the medium. Profile of laccase production by T. hirsuta SYBC-L19 with dual carbon sources in flask as well as in bioreactor is shown in Fig. 1. The peak activity of laccase in both cultivation conditions occurred on day $8,7.8 \mathrm{U} / \mathrm{ml}$ in flask (Fig. 1A) and $11 \mathrm{U} / \mathrm{ml}$ by fungus $\mathrm{L} 19$ in bioreactor (Fig. 1B), respectively. Along with the fungal cultivation, $\mathrm{pH}$ of the medium increased steadily from 4.3 on day 3 to 6.1 on day 10 while reducing sugar content reduced rapidly from $18 \mathrm{~g} / \mathrm{l}$ on day 3 to $3 \mathrm{~g} / \mathrm{l}$ on day 6 , corresponding to the accumulation of laccase activity during this phase (Fig. 1B). At the same time, an interesting phenomenon was observed that the green color of the medium caused by water hyacinth gradually faded with the laccase activity going up, suggesting green color removal might be correlated with laccase activity. Therefore, laccase was purified to further study its properties and application in decolorization of chlorophyll. Three-step purification scheme was adopted to purify laccase from the culture broth obtained above. Saturation of $80 \%$ ammonia sulfate successfully precipitated most laccase protein (60\% of total activity), which was subsequently collected using centrifugation $\left(8,000 \mathrm{~g}\right.$ for $10 \mathrm{~min}$ at $\left.4^{\circ} \mathrm{C}\right)$, re-dissolution, and dialysis (molecular weight cut-off 10,000). The collected laccase after precipitation was then loaded on a HiTrap DEAE FF anion exchange column pre-equilibrated with citric-phosphate buffer ( $\mathrm{pH}$ 6.0), from which three peaks $(a, b, c)$ showed up with only peak a having laccase activity (Fig. 2A). Afterward, Superdex 75 10/300 gel filtration column was employed to further separate collected laccase from peak a on HiTrap DEAE FF column. As found in Fig. 2B, three additional peaks appeared along with a peak a that contained laccase activity. The fractions with laccase activity were pooled and subjected to SDS-PAGE for purity confirmation (Fig. 2C), from which pure laccase was verified with molecular mass estimated as $68 \mathrm{kDa}$, similar to that of other fungal laccases (Garcia et al., 2007; Ko et al., 2001; Telke et al., 2010). Through three steps of purification, laccase was recovered up to $40 \%$ with purification fold of 9.51 and specific activity of $382.69 \mathrm{U} / \mathrm{mg}$.
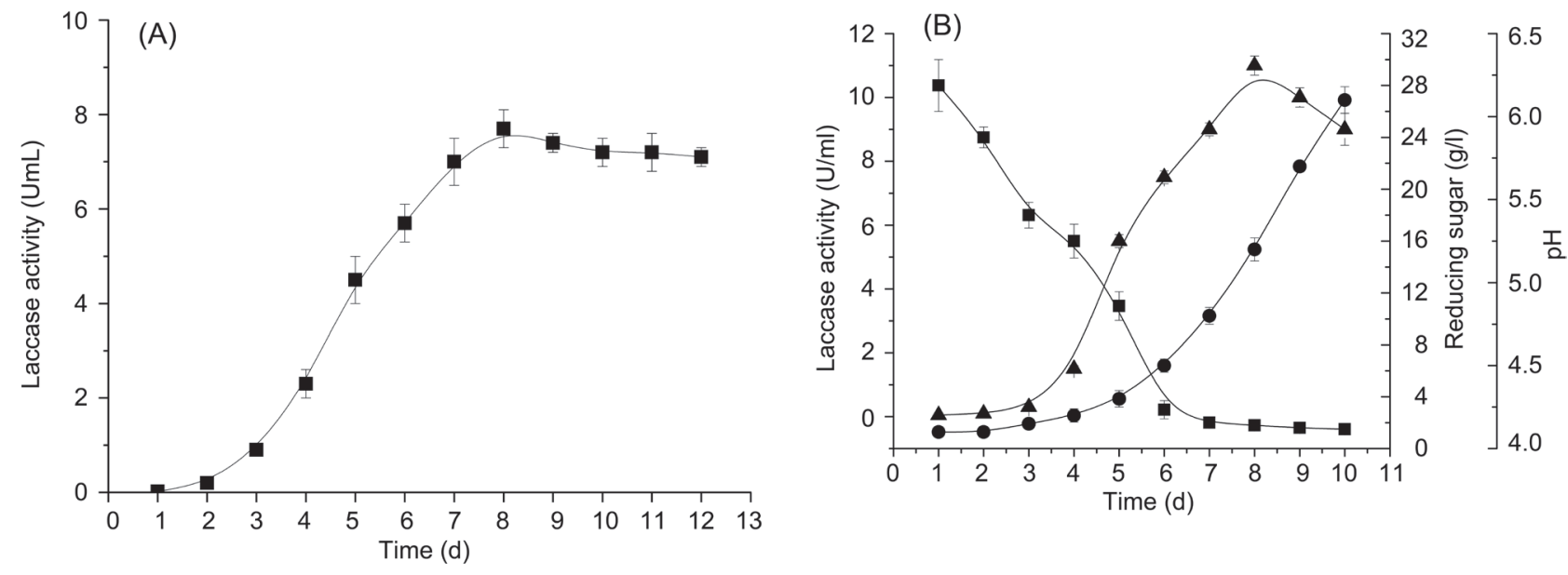

Fig. 1. Profile of laccase production by Trametes hirsuta L19 in flask (A) and in 5-1 stirred reactor (B). Symbols in this figure represent: laccase activity $(\boldsymbol{\Lambda}), \mathrm{pH}(\bullet)$, and reducing $\operatorname{sugar}(\boldsymbol{\bullet})$. 

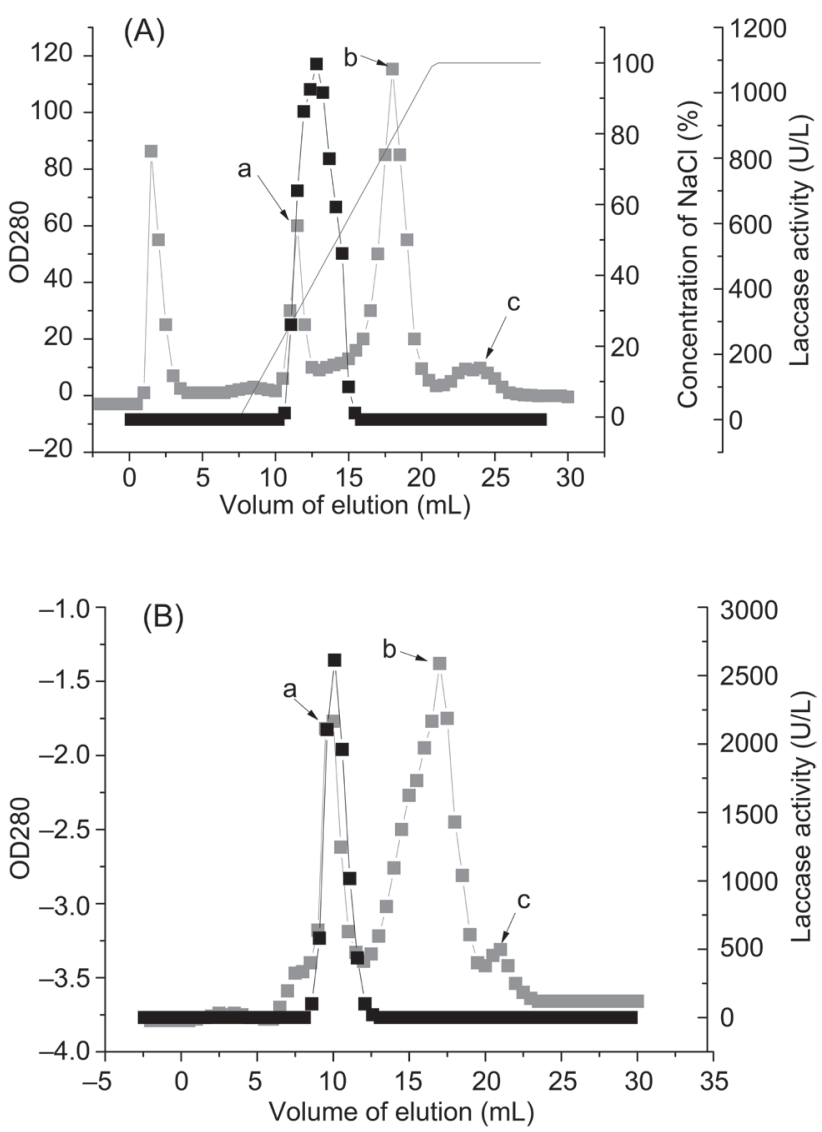

The detailed information of laccase purification from culture broth is summarized in Table I.

Partial properties of purified laccase. Fig. 3 shows profiles of laccase activity at various temperatures and $\mathrm{pH}$ values. The purified laccase exhibited relative high activity as above $60 \%$ when temperature was from 30 to $80^{\circ} \mathrm{C}$ with the highest activity occurring at around $60^{\circ} \mathrm{C}$ (Fig. 3A). After 1-h incubation at various temperatures below $70^{\circ} \mathrm{C}$, the residual activity of laccase was still as high as over $60 \%$, while $80^{\circ} \mathrm{C}$ would decrease laccase activity very fast, as indicated in the Fig. 3A. Activity of the purified laccase was dramatically inactivated after being incubated briefly at $90^{\circ} \mathrm{C}$ (data now shown). The purified laccase was most active between pH 3-5 towards substrate DMP and was relatively less active when $\mathrm{pH}$ was below 2 or above 6 (Fig. 3B). The optimal $\mathrm{pH}$ appeared to be around 3 for the laccase.
(C)

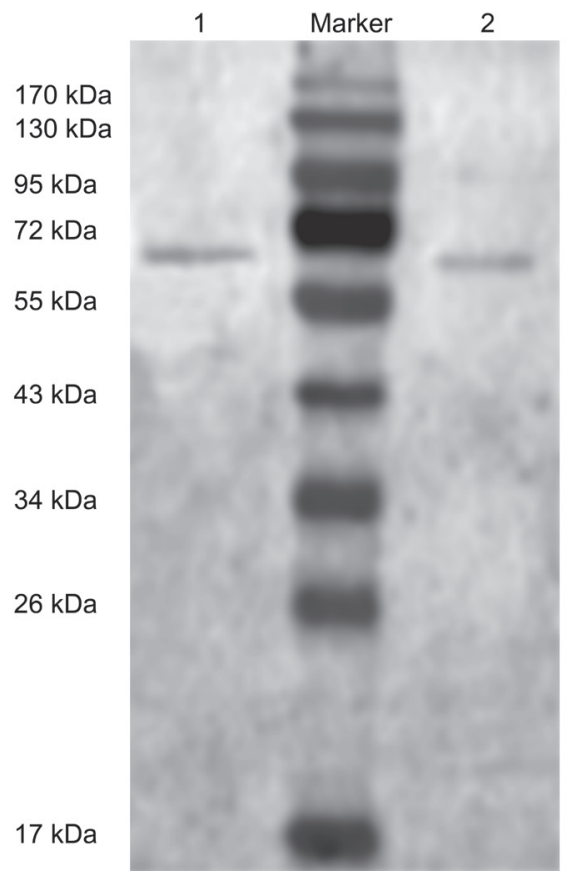

Fig. 2. Purification profile of laccase on ion-exchange column (A) and gel-filtration column (B) and SDS-PAGE of purified laccase (C). Symbols in this figure represent: OD280 ( $\square)$, concentration of $\mathrm{NaCl}$, and laccase activity $(\square)$.

The residual laccase activity was over $80 \%$ after being incubated for $1 \mathrm{~h}$ in $\mathrm{pH}$ range $4-8$ (Fig. 3B). These data showed that the purified laccase can catalyze under acidic condition with a wide temperature range, and it has excellent stability towards high temperature and neutral $\mathrm{pH}$. Similar results have also been reported for other fungal laccases that preserve activity under unfavorable pHs (Liers et al., 2007; Liu et al., 2013; Wang et al., 2010; Xiao et al., 2003).

Decolorization of chlorophyll catalyzed by laccase. Full wavelength scanning for untreated and laccase-treated chlorophyll is shown in Fig. 4. The UV-vis spectra of the chlorophyll solution without laccase treatment displayed two major absorption peaks as seen in Fig. 4A: $410 \mathrm{~nm}$ and $663 \mathrm{~nm}$ (typical absorbance spectra of chlorophyll $a$ with its chemical structure shown in Fig. 4B). The appearance of the untreated chlorophyll

Table I

Purification scheme of extracellular laccase from the culture broth by fungus Trametes hirsuta SYBC-L19

\begin{tabular}{|l|c|c|c|c|c|}
\hline \multicolumn{1}{|c|}{ Step } & $\begin{array}{c}\text { Total activity } \\
(\mathrm{U})\end{array}$ & $\begin{array}{c}\text { Total protein } \\
(\mathrm{mg})\end{array}$ & $\begin{array}{c}\text { Specific activity } \\
(\mathrm{U} / \mathrm{mg})\end{array}$ & $\begin{array}{c}\text { Purification } \\
\text { fold }\end{array}$ & $\begin{array}{c}\text { Recovery } \\
(\%)\end{array}$ \\
\hline Crude laccase & 1000 & 24.84 & 40.26 & 1.00 & 100 \\
\hline Precipitation & 782 & 14.67 & 53.31 & 1.32 & 78.2 \\
\hline DEAE FF & 508 & 3.31 & 153.47 & 3.81 & 50.8 \\
\hline Superdex 75 & 398 & 1.04 & 382.69 & 9.51 & 39.8 \\
\hline
\end{tabular}



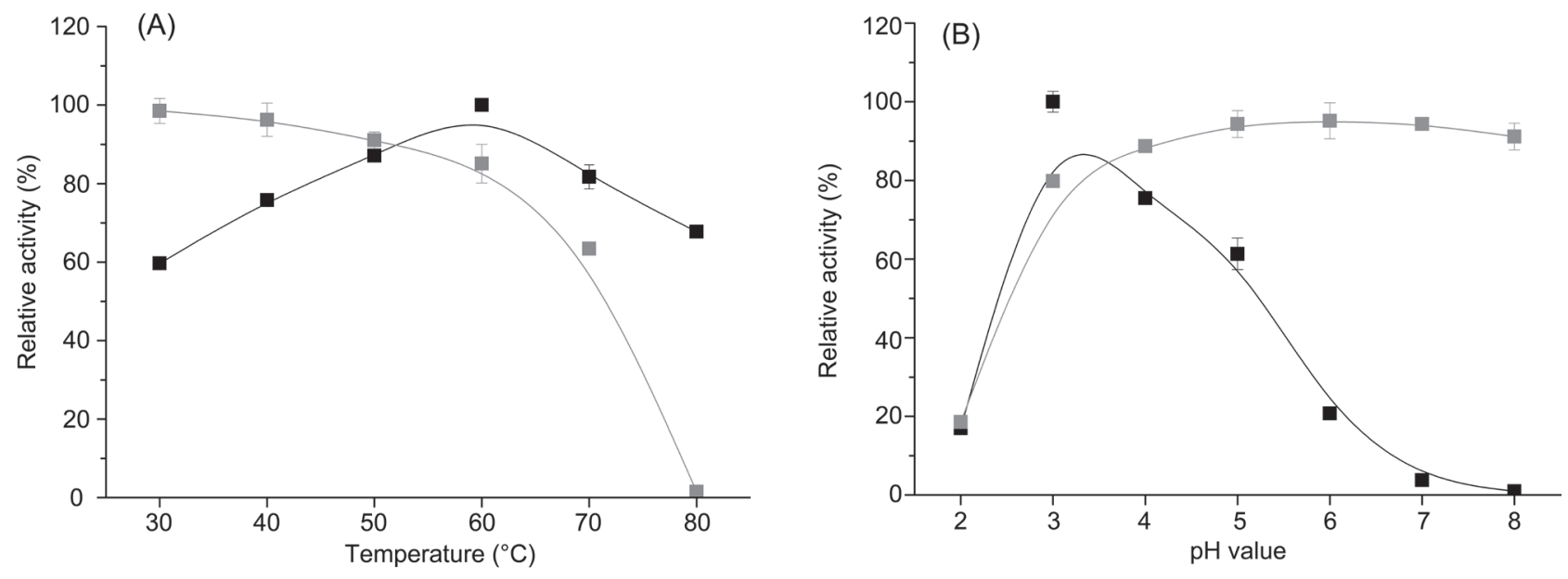

Fig. 3. Temperature optima ( $\square)$ and thermal stability ( $\square$ ) of the purified laccase (A).

$\mathrm{pH}$ optima ( $\mathbf{\square})$ and $\mathrm{pH}$ stability ( $\square$ ) of the purified laccase (B).

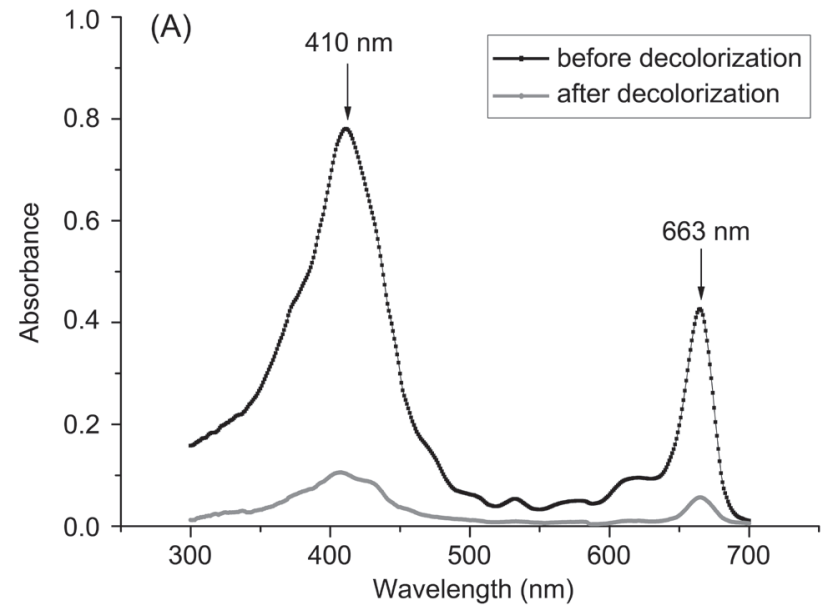

(C)
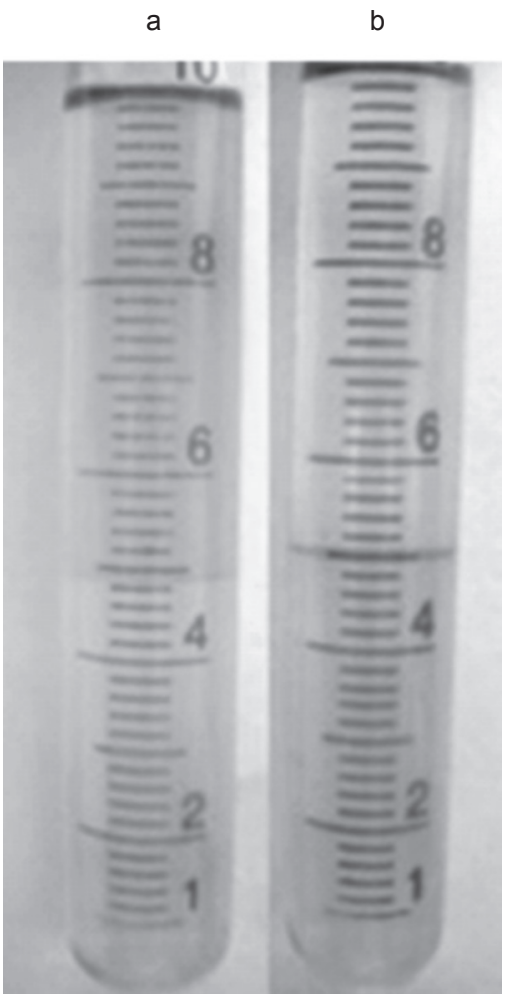

(B)

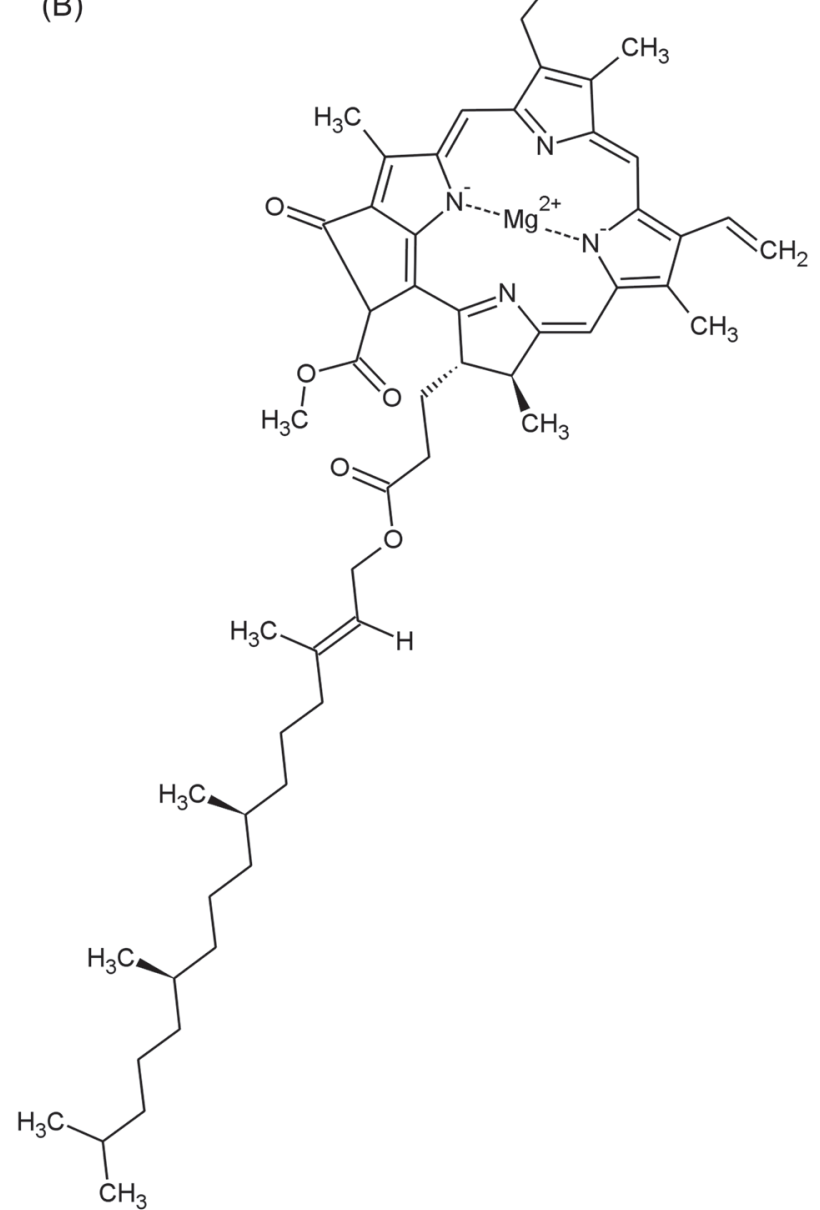

Fig. 4. (A) UV-vis spectra of hexane-extracted chlorophyll treated with deactivated (black line) and active purified laccase $(10 \mathrm{U} / \mathrm{mL})$ from Trametes hirsuta SYBC-L19 (red line) in vitro. (B) Chemical structure of chlorophyll $a$. (C) Pictures of hexane-extracted chlorophyll treated with deactivated (a) and active laccase purified from Trametes hirsuta SYBC-L19 (b) in vitro. Reactions were conducted at $50^{\circ} \mathrm{C}$ and $\mathrm{pH} 4.0$. 

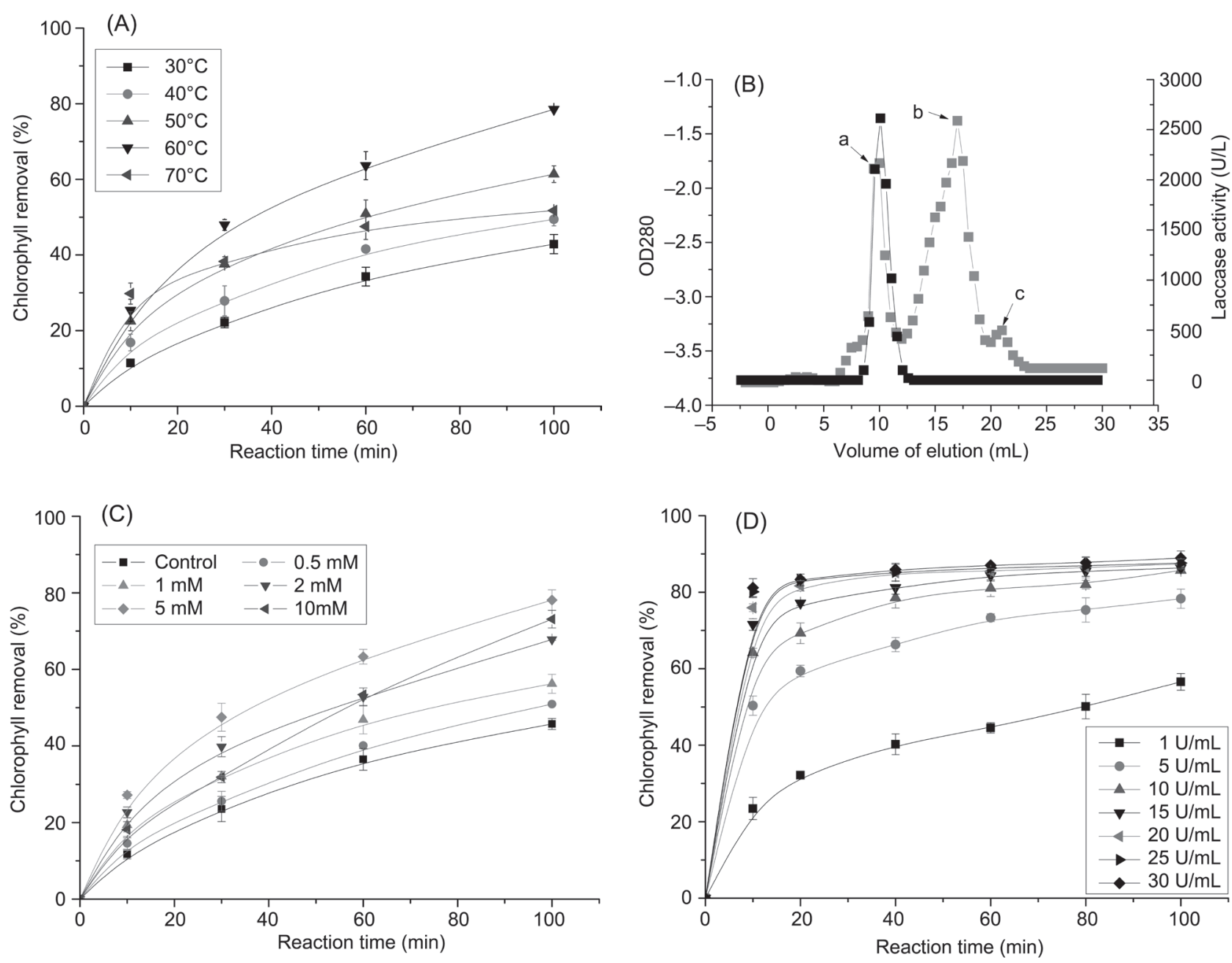

Fig. 5. Effect of temperature (A), pH (B), vanillin (C), and laccase loading (D) on laccase-catalyzed decolorization of chlorophyll. Reactions were conducted at $50^{\circ} \mathrm{C}$ and $\mathrm{pH} 4.0$ except for $\mathrm{A}$ and $\mathrm{B}$.

solution was green (Fig. 4C, upper layer in test tube a). Chlorophyll $a$ mainly absorbs violet, blue, and red light while reflecting green light, hence its green appearance. The laccase-treated chlorophyll solution showed a dramatic reduction in absorbance at $410 \mathrm{~nm}$ and $663 \mathrm{~nm}$ (Fig. 4A), and there was a nearly complete disappearance of visible green color (Fig. 4C, upper layer in tube b). As seen in the bottom layer of tube b (Fig. 4C), derivatives of the laccase-mediated decolorization of chlorophyll were formed and not soluble in hexane. The derivatives were a different color compared with the untreated chlorophyll extract in tube a. The change in the UV-vis spectra and the observed loss of green color in the treated sample suggest that spinach chlorophyll was decolorized by T. hirsuta SYBC-L19 laccase.

Effect of influencing factors on laccase-catalyzed decolorization of chlorophyll. Temperature Reaction temperature might not only affect laccase activity towards the substrate DMP but also the process of chlorophyll decolorization as shown in Fig. 5A. Decolorization of chlorophyll experienced an increase along with the reaction temperatures increasing from $30-60^{\circ} \mathrm{C}$ but not for $70^{\circ} \mathrm{C}$. The optimal temperature for chlorophyll decolorization was found to be at $60^{\circ} \mathrm{C}$, while the worst at $30^{\circ} \mathrm{C}$, which is in accordance with the optimal temperature for laccase activity towards DMP (Fig. 3A). As high as $80 \%$ decolorization of chlorophyll was obtained after 100 -min reaction by laccase at $60^{\circ} \mathrm{C}$. The highest decolorization rate showed up at $70^{\circ} \mathrm{C}$ within the first 10 -min reaction, while the rate slowed down dramatically at longer time. The decreased decolorization rate might ascribe to the altered molecular configuration of laccase enzyme when exposed to higher temperature.

$p H$ Like temperature, $\mathrm{pH}$ is another critical factor for enzyme-involved process. Fig. 5B reflects the results of chlorophyll decolorization by laccase under various $\mathrm{pH}$ conditions. The purified laccase transformed chlorophyll at high rate at $\mathrm{pH} 4,5$, and 6 , while the efficiency was markedly reduced at $\mathrm{pH} 3,7$, and 8 . At $\mathrm{pH}$ 7 and 8 , the performance was the worst because laccase lost activity in this $\mathrm{pH}$ range (Fig. 3B). The best performance was shown to be at $\mathrm{pH} 6.0$, resulting in $60 \%$ decolorization of chlorophyll within a 10 -min reaction. 
Table II

Effect of various metal salts (final concentration of 1 and $10 \mathrm{mM}$ ) on laccase activity and subsequent laccase-mediated decolorization of chlorophyll after 1-h treatment

\begin{tabular}{|l|c|c|c|c|}
\hline \multirow{2}{*}{ Metal Salts } & \multicolumn{2}{|c|}{ Relative Laccase Activity (\%) } & \multicolumn{2}{c|}{ Rate of Decolorization (\%) } \\
\cline { 2 - 5 } & $1 \mathrm{mM}$ & $10 \mathrm{mM}$ & $1 \mathrm{mM}$ & $10 \mathrm{mM}$ \\
\hline Control & $100 \pm 1.23$ & $100 \pm 1.23$ & $80.74 \pm 2.75$ & $80.74 \pm 2.75$ \\
\hline Calcium chloride & $104.17 \pm 3.54$ & $89.17 \pm 1.18$ & $74.81 \pm 1.26$ & $60.70 \pm 4.41$ \\
\hline Barium chloride & $105.83 \pm 3.54$ & $100.00 \pm 2.36$ & $82.96 \pm 0.84$ & $84.67 \pm 2.03$ \\
\hline Ferrous chloride & $83.33 \pm 1.12$ & $18.33 \pm 1.76$ & $73.11 \pm 1.15$ & $69.70 \pm 1.94$ \\
\hline Ferric chloride & $97.50 \pm 1.18$ & $68.33 \pm 2.21$ & $78.00 \pm 0.52$ & $77.26 \pm 1.36$ \\
\hline Cobalt chloride & $101.67 \pm 9.43$ & $90.83 \pm 3.54$ & $76.00 \pm 1.05$ & $72.44 \pm 0.42$ \\
\hline Manganese chloride & $103.33 \pm 0.75$ & $95.83 \pm 1.18$ & $74.81 \pm 1.26$ & $60.70 \pm 4.41$ \\
\hline Zinc sulfate & $102.50 \pm 3.54$ & $97.50 \pm 3.54$ & $83.19 \pm 2.94$ & $81.41 \pm 0.31$ \\
\hline Copper sulfate & $104.17 \pm 3.54$ & $95.83 \pm 1.18$ & $81.78 \pm 0.21$ & $77.63 \pm 1.26$ \\
\hline Magnesium sulfate & $102.50 \pm 1.18$ & $104.17 \pm 1.18$ & $75.19 \pm 1.99$ & $71.78 \pm 3.52$ \\
\hline Aluminum nitrate & $102.50 \pm 3.54$ & $103.33 \pm 2.36$ & $81.78 \pm 0.81$ & $71.85 \pm 2.63$ \\
\hline Lead acetate & $100.83 \pm 3.54$ & 98.33 & $80.74 \pm 0.21$ & $79.93 \pm 1.52$ \\
\hline
\end{tabular}

Reactions were conducted at $50^{\circ} \mathrm{C}$ and $\mathrm{pH} 4.0$. Laccase dosage was $10 \mathrm{U} / \mathrm{mL}$.

Table III

Effect of various mediators on laccase-mediated decolorization of chlorophyll after 1-h treatment

\begin{tabular}{|l|c|c|c|}
\hline \multirow{2}{*}{ Mediator } & \multicolumn{3}{c|}{ Final concentration (mM) } \\
& 0.5 & \multicolumn{3}{c|}{ Rate of decolorization (\%) } \\
\hline control & $36.5 \pm 2.54$ & $36.5 \pm 2.54$ & $36.5 \pm 2.54$ \\
\hline 4-Hydroxybenzoic acid & $43.43 \pm 3.21$ & $38.54 \pm 1.24$ & $37.08 \pm 0.34$ \\
\hline Resorcine & $39.12 \pm 1.92$ & $46.54 \pm 4.12$ & $49.72 \pm 3.28$ \\
\hline DMP & $36.5 \pm 1.58$ & $37.32 \pm 2.83$ & $32.61 \pm 1.74$ \\
\hline ABTS & $38.24 \pm 0.79$ & $48.32 \pm 0.24$ & $45.27 \pm 2.38$ \\
\hline Ascorbic acid & $37.43 \pm 2.21$ & $42.36 \pm 2.36$ & $40.83 \pm 0.27$ \\
\hline Gallic acid & $34.74 \pm 4.78$ & $30.34 \pm 1.54$ & $28.36 \pm 0.48$ \\
\hline Ferulic acid & $37.26 \pm 2.36$ & $41.98 \pm 4.62$ & $42.09 \pm 2.83$ \\
\hline Vanillin & $40.13 \pm 1.23$ & $52.81 \pm 0.43$ & $63.31 \pm 1.76$ \\
\hline 4-Nitrophenol & $29.43 \pm 1.46$ & $28.56 \pm 1.76$ & $30.45 \pm 0.22$ \\
\hline Hydroquinone & $42.87 \pm 2.31$ & $38.12 \pm 2.38$ & $35.29 \pm 1.46$ \\
\hline Pyrocatechol & $33.24 \pm 0.42$ & $30.26 \pm 3.24$ & $29.36 \pm 3.46$ \\
\hline Syringaldehyde & $35.34 \pm 1.27$ & $32.28 \pm 4.58$ & $31.87 \pm 2.58$ \\
\hline
\end{tabular}

Reactions were conducted at $50^{\circ} \mathrm{C}$ and $\mathrm{pH}$ 4.0. A reduced laccase dosage of $1 \mathrm{U} / \mathrm{mL}$ was applied.

Metal ions The experimental data demonstrated that most metal ions, from $1 \mathrm{mM}$ to $10 \mathrm{mM}$, did not have much influence on laccase activity as well as chlorophyll decolorization (Table II). It has been reported that some fungal laccases can be significantly de-activated by $\mathrm{Fe}^{2+}$ even at trace concentration (Wang et al., 2010). The laccase activity in this study was decreased by more than $80 \%$ when exposed to high concentration of $\mathrm{Fe}^{2+}(10 \mathrm{mM})$, which was in accordance with previous reports (Wang et al., 2010; Zhang et al., 2010). These results suggest that laccase from L19 is metal-tolerant (except for $\mathrm{Fe}^{2+}$ ) resembling the features of those reported fungal laccases (Zhu et al., 2011). However, $10 \mathrm{mM}$ of $\mathrm{Fe}^{2+}$ did not influence chlorophyll decolorization too much, still yielding $77 \%$ decolorization. Metal ions tend to influence the decolorization of chlorophyll by affecting laccase activity.

Mediator The effect of various mediators on laccase-mediated chlorophyll decolorization was investigated at three concentration levels, and the results are depicted in Table III. Apparently, not all mediators could enhance the decolorization process (Yamauchi et al., 2004). Vanillin was ranked the first and resorcine the second among these mediators in terms of facili- 
tating chlorophyll decolorization. The decolorization rate was doubled in the presence of $5.0 \mathrm{mM}$ vanillin . Higher decolorization rate was observed when vanillin increased from 0.5 to $5.0 \mathrm{mM}$, while $10 \mathrm{mM}$ vanillin slightly inhibited the transformation rate during the first 1-h reaction (Fig. 5C). After 100-min laccase treatment in the presence of $5.0 \mathrm{mM}$ vanillin, approximately $80 \%$ chlorophyll was degraded. Some mediators, namely 4-nitrophenol, pyrocatechol, and syringaldehyde, seem to have an inhibiting effect on the decolorization process.

Enzyme loading. The level of chlorophyll removal ranged widely at various laccase dosages, especially when the reaction just initiated, as shown in Fig. 5D. Higher laccase dosage apparently led to greater chlorophyll removal during the first 10 minutes of reaction when laccase dosage was below $20 \mathrm{U} / \mathrm{ml}$. Over $80 \%$ chlorophyll removal was achieved in less than $10 \mathrm{~min}$ utes when $30 \mathrm{U} / \mathrm{ml}$ laccase was applied, indicating treatments with higher laccase activity would require less time to reach maximum chlorophyll removal but may not be cost effective as more enzymes have to be used .

Laccase source. Investigations on chlorophyll degradation by other fungal laccases in the form of crude extract were further performed. Table IV illustrates the effect of different laccases on chlorophyll decolorization at two enzyme levels. In general, Trametes laccases and Pycnoporus laccases had similar effectiveness regarding chlorophyll degradation while Shiraia laccase was less effective, indicating different laccases vary in their catalytic abilities toward the same substrate. The highest chlorophyll removal, approximately $81 \%$ and $88 \%$, was observed for the fungus SYBC-L3 laccase and the fungus SYBC-L1 laccase, respectively. Laccases from white-rot fungi had a higher capability of degreening chlorophyll than that from Shiraia sp. SUPER-H168, which achieved $50-60 \%$ chlorophyll removal. When laccase level was increased from $5 \mathrm{U} / \mathrm{ml}$ to $10 \mathrm{U} / \mathrm{ml}$, chlorophyll decolorization rate increased by around $10 \%$ for all fungal

Table IV

Decolorization of chlorophyll following 1-h treatment with crude laccase extract from different fungi

\begin{tabular}{|l|c|c|}
\hline \multirow{2}{*}{\multicolumn{1}{|c|}{ Fungal strain }} & \multicolumn{2}{c|}{$\begin{array}{c}\text { Chlorophyll } \\
\text { decolorization }(\%)\end{array}$} \\
\cline { 2 - 3 } & $5 \mathrm{U} / \mathrm{mL}$ & $10 \mathrm{U} / \mathrm{mL}$ \\
\hline Trametes trogii SYBC-L1 & $80.53 \pm 0.75$ & $86.53 \pm 2.82$ \\
\hline Pycnoporus sp. SYBC-L3 & $81.20 \pm 0.19$ & $87.73 \pm 2.26$ \\
\hline Trametes hirsuta SYBC-L5 & $72.53 \pm 0.38$ & $80.40 \pm 3.96$ \\
\hline Pycnoporus cinnabarinus SYBC-L7 & $78.80 \pm 2.07$ & $86.80 \pm 1.70$ \\
\hline Trametes hirsuta SYBC-L19 & $71.07 \pm 0.57$ & $82.53 \pm 2.26$ \\
\hline Shiraia sp. SUPER-H168 & $52.8 \pm 3.77$ & $62.13 \pm 2.26$ \\
\hline
\end{tabular}

Reactions were conducted at $50^{\circ} \mathrm{C}$ and $\mathrm{pH} 4.0$ at two activity levels, $5 \mathrm{U} / \mathrm{mL}$ or $10 \mathrm{U} / \mathrm{mL}$. laccases investigated. It should be noted that the comparison presented above was made with enzymes in different purity forms although they were all normalized to the same activity levels in the experiments.

\section{Discussion}

Comprehensive utilization and conversion of lignocellulosic wastes into useful value-adding products have been worldwide research foci that meanwhile help reduce their environmental pollution (Bustamante et al., 2012). One approach is to take these wastes as media for cultivation of ligninolytic fungi via liquid/ solid state fermentation with some enzymes simultaneously produced (Liu et al., 2013; Singh et al., 2010). Some lignocellulosic wastes, such as chestnut shell, barley bran, and grape seeds/stalks, have been successfully used for laccase production by white-rot fungi (Gómez et al., 2005; Lorenzo et al., 2002). Up to date, there are only a few studies on the utilization of water hyacinth, a lignocellulosic waste which is yearly produced in large quantity in watersides in south China. As far as we know, most of water hyacinth has been discarded as useless waste or burned up. Therefore, the wild fungus T. hirsuta SYBC-L19 might be a promising strain concerning recycling lignocellulosic waste water hyacinth as a supplementary carbon source for laccase production not only in flask but also in bioreactor.

The high cost of laccase production has been regarded as an obstacle to its widespread use for industrial and environmental purposes. It is thus of practical significance to optimize laccase production by all kinds of means, e.g., medium optimization. Conventional laccase production procedure usually refers to a single carbon source. The results of this study, however, showed that dual carbon sources might serve as a cost-effective strategy for enhancing laccase productivity. Cheap lignocellulosic wastes, like water hyacinth in this study, are supposed to function both as carbon source and laccase secretion inducer in addition to some already known inducers, e.g. vanillin (de la Rubia et al., 2002). From the culture broth of L19, a single laccase was purified through a three-step purification scheme. Properties of the purified laccase were, however, demonstrated to be highly similar to that of other fungal laccases (Baldrian, 2006), favoring optimal $\mathrm{pH}$ scale $2.0-8.0$, optimal temperature in the range of $40-80^{\circ} \mathrm{C}$ for oxidative reactions, and with the molecule weight ranging from 40 to $80 \mathrm{kDa}$ for majority of fungal laccases.

Chlorophylls do not accumulate in nature because of biological and microbial transformation, however direct decolorization by laccase has not been reported. In addition to a number of reported substrates of laccase, we for the first time demonstrated chlorophyll $a$ 
was also a substrate for laccase in this study. Laccasemediated chlorophyll $a$ decolorization led to disappearance of two characteristic absorbance peaks at 410 and $663 \mathrm{~nm}$. The chlorophyll $a$ was hence decolorized to colorless derivatives. Among several influential factors examined, including temperature, $\mathrm{pH}$, metal ions, mediators, and enzyme dosage, laccase activity seemed to be the most significant parameter controlling chlorophyll decolorization. Furthermore, we showed that other laccase sources were also capable of degrading chlorophyll $a$. A study by Ahmadi et al. (Ahmadi et al., 2009) indicated that chlorophyll degradation might be associated with laccase and they hypothesized that enhanced expression of laccase gene might lead to chlorophyll degradation in miniature roses exposed to ethylene. However, in the existing body of research, a demonstrated direct degradation of chlorophyll by laccase did not exist, until now.

Decolorization of chlorophyll mediated by peroxidase has been previously documented (Yamauchi et al., 2004). Some colorless low-molecular compounds are concomitantly formed, namely fluorescent chlorophyll catabolite (FCC) and bilirubin-like compounds (BLC), likely via peroxidase-mediated opening of chlorophyll structure (Yamauchi et al., 2004). It is believed that $\mathrm{H}_{2} \mathrm{O}_{2}$ is needed by peroxidase to form a phenoxy radical for the above chlorophyll oxidation, from which lowmolecular colorless derivates are eventually produced (Yamauchi et al., 2004). Available data reveal that most oxidative reactions of substrates by laccase, different from peroxidase, in the presence of oxygen are not $\mathrm{H}_{2} \mathrm{O}_{2}$ dependent (Colosi et al., 2009; Lu et al., 2009). Therefore, degradation of chlorophyll by laccase might be achieved via different oxidative pathways. It would be of interest in the future study to indentify the metabolic intermediates of chlorophyll using finer analytic methods.

\section{Acknowledgements}

This work was financially supported by the National High Technology and Development Program of China (863 Program, grant No., 2010AA101501), The National Natural Science Foundation of China (Grand No. 21045007), and Wuxi Science and Technology Support Program of Social Development Project (CSE01N1210).

\section{Literature}

Ahmadi N., H. Mibus and M. Serek. 2009. Characterization of ethylene-induced organ abscission in F1 breeding lines of miniature roses (Rosa hybrida L.). Postharvest. Biol. Tec. 52: 260-266.

Baldrian P. 2006. Fungal laccases - occurrence and properties. FEMS. Microbiol. Rev. 30: 215-242.

Bustamante M.A., A.P. Restrepo, J.A. Alburquerque, M.D. PérezMurcia, C. Paredes, R. Moral and M.P. Bernal. 2012. Recycling of anaerobic digestates by composting: effect of the bulking agent used. J. Clean. Prod. 47: 61-69.

Chen M., M. Schliep, R.D. Willows, Z.L. Cai, B.A. Neilan and H. Scheer. 2010. A Red-Shifted Chlorophyll. Science 329: 1318-1319.
Colosi L.M., R.A. Pinto, Q. Huang and W.J. Weber. 2009. Peroxidase-mediated degradation of perfluorooctanoic acid. Environ. Toxicol. Chem. 28: 264-271.

Couto S.R. and M.Á. Sanromán. 2007. The effect of violuric acid on the decolourization of recalcitrant dyes by laccase from Trametes hirsuta. Dyes. Pigments 74: 123-126.

Cristóvão R.O., A.P.M. Tavares, L.A. Ferreira, J.M. Loureiro, R.A.R. Boaventura and E.A. Macedo. 2009. Modeling the discoloration of a mixture of reactive textile dyes by commercial laccase. Bioresour. Technol. 100: 1094-1099.

de la Rubia T., E. Ruiz, J. Pérez and J. Martínez. 2002. Properties of a laccase produced byPhanerochaete flavido-alba induced by vanillin. Arch. Microbiol. 179: 70-73.

Eggert C., U. Temp and K. Eriksson. 1996. The ligninolytic system of the white rot fungus Pycnoporus cinnabarinus: purification and characterization of the laccase. Appl. Environ. Microbiol. 62: 1151-1158

Faraco V., C. Ercole, G. Festa, P. Giardina, A. Piscitelli and G. Sannia. 2008. Heterologous expression of heterodimeric laccase from Pleurotus ostreatus in Kluyveromyces lactis. Appl. Microbiol. Biotechnol. 77: 1329-1335.

Gómez J., M. Pazos, S. Rodríguez Couto and M.Á. Sanromán. 2005. Chestnut shell and barley bran as potential substrates for laccase production by Coriolopsis rigida under solid-state conditions. J. Food. Eng. 68: 315-319.

Garcia T.A., M.F. Santiago and C.J. Ulhoa. 2007. Studies on the Pycnoporus sanguineus CCT-4518 laccase purified by hydrophobic interaction chromatography. Appl. Microbiol. Biotechnol. 75: 311-318. Hsu C.-A., T.-N. Wen, Y.-C. Su, Z.-B. Jiang, C.-W. Chen and L.-F. Shyur. 2012. Biological degradation of anthroquinone and azo dyes by a novel laccase from Lentinus sp. Environ. Sci. Technol. 46: 5109-5117.

Hynninen P.H., V. Kaartinen and E. Kolehmainen. 2010. Horseradish peroxidase-catalyzed oxidation of chlorophyll a with hydrogen peroxide: Characterization of the products and mechanism of the reaction. BBA-Biogenetics 1797: 531-542.

Ko E.M., Y.E. Leem and H.T. Choi. 2001. Purification and characterization of laccase isozymes from the white-rot basidiomycete Ganoderma lucidum. Appl. Microbiol. Biotechnol. 57: 98-102.

Liers C., R. Ullrich, M. Pecyna, D. Schlosser and M. Hofrichter. 2007. Production, purification and partial enzymatic and molecular characterization of a laccase from the wood-rotting ascomycete Xylaria polymorpha. Enzyme. Microb. Technol. 41: 785-793.

Litthauer D., M.J. van Vuuren, A. van Tonder and F.W. Wolfaardt. 2007. Purification and kinetics of a thermostable laccase from Pycnoporus sanguineus (SCC 108). Enzyme. Microb. Technol. 40: 563-568.

Liu J., Y. Cai, X. Liao, Q. Huang, Z. Hao, M. Hu, D. Zhang and Z. Li. 2013. Efficiency of laccase production in a 65-liter air-lift reactor for potential green industrial and environmental application. J. Clean. Prod. 39: 154-160.

Liu J., M.L. Wang, B. Tonnis, M. Habteselassie, X. Liao and Q. Huang. 2013. Fungal pretreatment of switchgrass for improved saccharification and simultaneous enzyme production. Bioresour. Technol. 135: 39-45.

Lorenzo M., D. Moldes, S. Rodriguez Couto and A. Sanroman. 2002. Improving laccase production by employing different lignocellulosic wastes in submerged cultures of Trametes versicolor. Bioresour. Technol. 82: 109-113.

Lu J., Q. Huang and L. Mao. 2009. Removal of acetaminophen using enzyme-mediated oxidative coupling processes: I. Reaction rates and pathways. Environ. Sci. Technol. 43: 7062-7067.

Martínez G.A., P.M. Civello, A.R. Chaves and M.A.C. Añón. 2001. Characterization of peroxidase-mediated chlorophyll bleaching in strawberry fruit. Phytochemistry 58: 379-387. 
Mayer A.M. and R.C. Staples. 2002. Laccase: new functions for an old enzyme. Phytochemistry 60: 551-565.

Pividori M.I., S. Gómez-Montes and S. Alegret. 2009. Determination of polyphenol index in wine based on laccase biocomposite biosensors. New Biotechnol. 25: S352-S352.

Sadhasivam S., S. Savitha and K. Swaminathan. 2010. Deployment of Trichoderma harzianum WL1 laccase in pulp bleaching and paper industry effluent treatment. J. Clean. Prod. 18: 799-806.

Santhiago M. and I.C. Vieira. 2007. 1-Cysteine determination in pharmaceutical formulations using a biosensor based on laccase from Aspergillus oryzae. Sensor. Actuat. B-Chem. 128: 279-285.

Singh A., S. Bajar, N.R. Bishnoi and N. Singh. 2010. Laccase production by Aspergillus heteromorphus using distillery spent wash and lignocellulosic biomass. J. Hazard. Mater. 176: 1079-1082.

Telke A., A. Kadam, S. Jagtap, J. Jadhav and S. Govindwar. 2010. Biochemical characterization and potential for textile dye degradation of blue laccase from Aspergillus ochraceus NCIM-1146. Biotechnol. Bioprocess Eng. 15: 696-703.

Tien M. and T.-K. Kirk. 1988. Lignin peroxidase of Phanerochaete chrysosporium. Method. Enzymol. 161: 238-249.
Wang Z.-X., Y.-J. Cai, X.-R. Liao, G.-J. Tao, Y.-Y. Li, F. Zhang and D.-B. Zhang. 2010. Purification and characterization of two thermostable laccases with high cold adapted characteristics from Pycnoporus sp. SYBC-L1. Proc. Biochem. 45: 1720-1729.

Xiao Y.Z., X.M. Tu, J. Wang, M. Zhang, Q. Cheng, W.Y. Zeng and Y.Y. Shi. 2003. Purification, molecular characterization and reactivity with aromatic compounds of a laccase from basidiomycete Trametes sp. strain AH28-2. Appl. Microbiol. Biotechnol. 60: 700-707. Yamauchi N., Y. Funamoto and M. Shigyo. 2004. Peroxidase-mediated chlorophyll degradation in horticultural crops. Phytochem. Rev. 3: 221-228.

Yang Y., Y. Ding, X. Liao and Y. Cai. 2013. Purification and characterization of a new laccase from Shiraia sp.SUPER-H168. Proc. Biochem. 48: 351-357.

Zhang G.-Q., Y.-F. Wang, X.-Q. Zhang, T.B. Ng and H.-X. Wang. 2010. Purification and characterization of a novel laccase from the edible mushroom Clitocybe maxima. Proc. Biochem. 45: 627-633.

Zhu Y.S., H.B. Zhang, M.L. Cao, Z.Z. Wei, F. Huang and P.J. Gao. 2011. Production of a thermostable metal-tolerant laccase from Trametes versicolor and its application in dye decolorization. Biotechnol. Bioprocess Eng. 16: 1027-1035. 
